\title{
Physical constraints of bath treatments of Atlantic salmon (Salmo salar) with a sea lice burden (Copepoda: Caligidae)
}

\author{
James W. Treasurer ${ }^{1}$, Andrew Grant ${ }^{1}$ \& Paul J. Davis ${ }^{2}$ \\ ${ }^{1}$ Marine Harvest McConnell, Lochailort, Inverness-shire PH38 4LZ, U.K,; ${ }^{2}$ Unilever Research, Colworth \\ Laboratory, Sharnbrook, Bedford MK44 1LQ, U.K.
}

Keywords: sea lice, Atlantic salmon, Salmo salar, bath application, dichlorvos, hydrogen peroxide

\begin{abstract}
Licensed medicines available in the U.K. for treating Atlantic salmon infested with sea lice, dichlorvos, azamethiphos, and hydrogen peroxide, can only be administered by bath application. Adverse reactions have been reported to bath treatments including mortalities, inappetance, reduction in growth and reduced louse sensitivity to dichlorvos. The physical constraints of bath treatments are examined and improvements recommended. Oxygen saturation was adequate during treatments but declined rapidly when the tarpaulin was removed. A chemical marker dispersed uniformally both horizontally and vertically in a cage within 5 mins of dispensing indicating dispersal of a medicine is rapid and adequate during treatment. The range in enclosed volumes in 86 treatments was 46 to $146 \%$ of theoretical, suggesting potential toxicity due to high concentrations at low volumes and the risk of reduced sensitivity at high volumes. Resídual concentrations of hydrogen peroxide varied from 50 to $400 \mathrm{ppm}$ from 5 to 15 mins after the tarpaulin was removed. Water exchange should be encouraged by aerating the cage and flushing at the end of treatment.
\end{abstract}

\section{Contents}

Introduction

Oxygen depletion

Rate and pattern of dispersal of chemotherpeutants within the cage

Variation in the volume of enclosed water

Residual medicine in the cage following treatment

Conclusions

Acknowledgements

References

\section{Introduction}

Sea lice (Copepoda: Caligidae), mainly Lepeophtheirus salmonis and Caligus elongatus are the principal disease threat to farmed Atlantic salmon, Salmo salar, in Ireland, Norway and Scotland (Pike, 1989; Costello, 1993) and North America (Johnson \& Albright, 1991), inducing mortalities and having serious effects on appetance and, consequently, growth. Figure 1 shows the depression in appetite (expressed as a percentage of body weight consumed per day) coinciding with bath treatments, and in week 23 also due to high sea lice infestation. Salmon of $3.1 \mathrm{~kg}$ mean weight were sampled weekly in the second year of the production cycle. Five fish were sampled in each of six cages selected at random. Lice graze the epidermal surface and, if left untreated, fish will die from osmoregulatory failure (Wootten, Smith \& Needham, 1982). Only three licensed medicines are currently routinely available with marketing authorisations and discharge consents for the treatment of fish infected with sea lice in the United Kingdom: dichlorvos marketed as Aquagard and azamethiphos as Salmosan (Novartis), and hydrogen peroxide either $35 \%$ or $50 \%$ concentration as Salartect (Brenntag U.K. Ltd) and Paramove (Solvay Interox). These medicines are applied as a bath, that is full enclosure of the net with a tarpaulin. The cage net is raised, oxygen supplied, the net enclosed with a tarpaulin, and a medicine such as dichlorvos added for a prescribed period. Bath treatment with current medicines may involve risk with several disadvantages: stress to fish, mortalities, loss of growth through starvation before treat"ment and inappetance following treatment (Fig. 1). There are logistical problems to the farmer as bath treatments are labour intensive. With use over a 


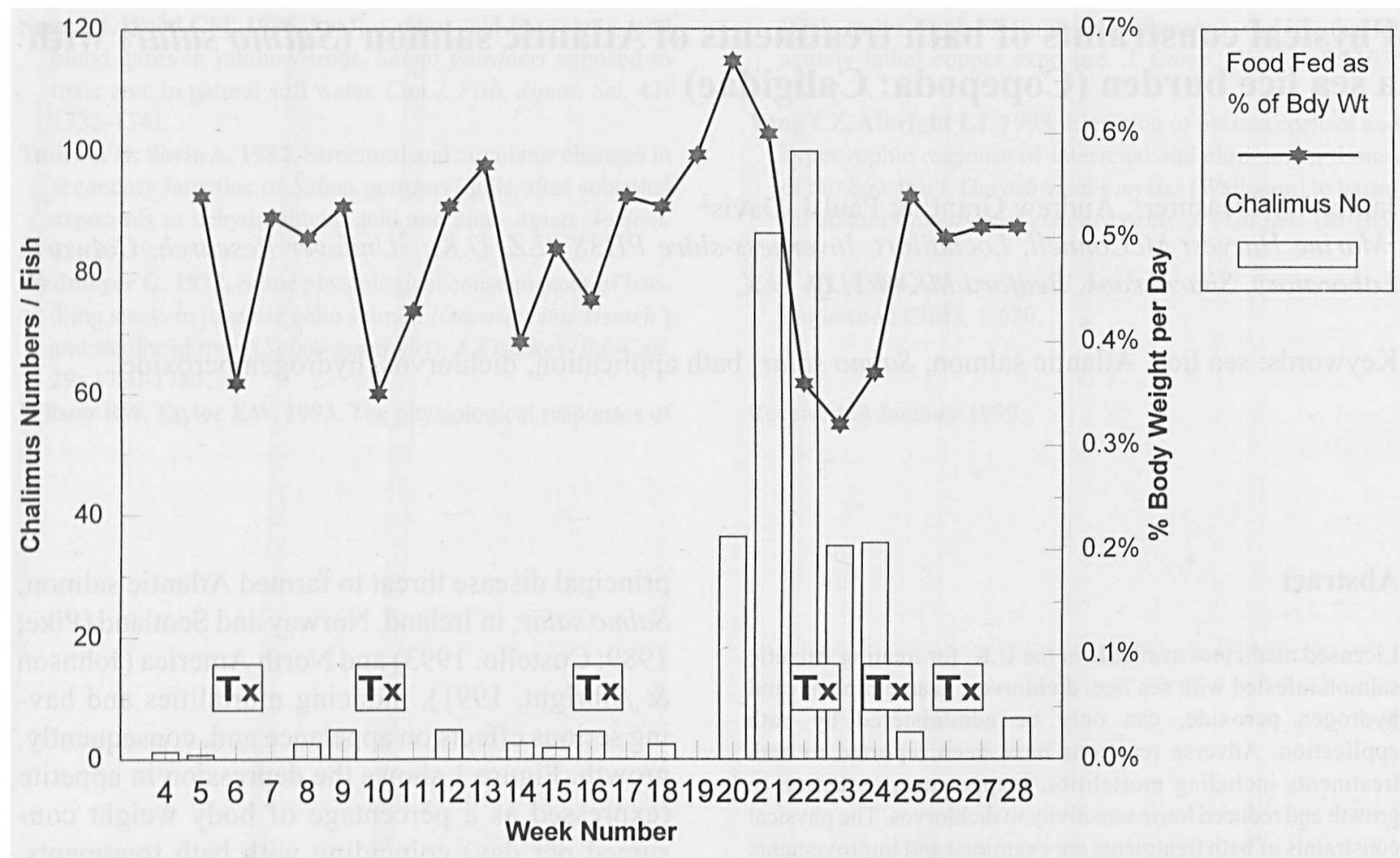

Fig. 1. Reduction in feed intake due to high chalimus numbers per fish and starvation during sea lice treatments with hydrogen peroxide (marked by $\mathrm{Tx}$ ).

prolonged period reduced sensitivity to the medicine such as dichlorvos may occur (Jones et al,, 1992). Mortalities have been experienced with bath treatments using different medicines, so the problem is not confined to the use of any one in particular. The licensing of another medicine, the pyrethroid Excis (Grampian Pharmaceuticals) is imminent. Although this is likely to be safer in use and is also effective against juvenile stages, the bath method of application will be used and therefore associated problems may still apply.

Other problems can arise during bath treatments, for example the variation in water volume enclosed by a tarpaulin. The approved concentration of Aquagard during treatment is $2 \mathrm{ppm}$ ( $1 \mathrm{ppm}$ dichlorvos) and the dimensions of the treatment tarpaulin are considered when calculating the volume of Aquagard required. In practice, the volume of the tarpaulin is highly variable and poor fills, perhaps due to net obstructions or tidal direction, can lead to fish mortality (pers. obs.).

Potential problems with bath treatments are examined here and results of experimental field test- ing of safety margins are discussed, namely (1), oxygen saturation, (2), rate and pattern of dispersal of the treatment medicine, (3), assessment of enclosed volume and therefore accurate dosing, and (4), the possible continued residence of medicine within the cage once the treatment has finished and the tarpaulin has been removed.

\section{Oxygen depletion}

Oxygen levels may be a contributory factor in fish mortalities and many farmers routinely use oxygen meters to monitor saturation. Burrowing behaviour into net pockets has been reported in some cases following treatment. Oxygen levels were measured during a treatment of salmon with a sea lice burden to assess horizontal and vertical variation in percentage saturation within the raised and enclosed net. 


\section{Methods}

Oxygen was measured during a normal sea lice treatment with hydrogen peroxide. The net on a $15 \mathrm{~m}^{2}$ cage was raised from $8 \mathrm{~m}$ to $3 \mathrm{~m}$ depth. One large circular oxygen ring was made from joining three $3 \mathrm{~m}$ sections and this was positioned by ropes lying on the bottom of the net in the middle of the cage. The cage held 76001 sea winter salmon of $3.1 \mathrm{~kg}$ mean weight. The experiment was conducted in September 1996 when water temperature was $13^{\circ} \mathrm{C}$ and salinity $32 \mathrm{ppt}$ at $2 \mathrm{~m}$ depth. Oxygen saturation was monitored with three Bobcat logging meters at 1 minute intervals, with probes located midway between the oxygen ring and the cage side and set at 3 depths: $0.5 \mathrm{~m}, 2 \mathrm{~m}$ and $2.8 \mathrm{~m}$ (the net bottom). 6001 of hydrogen peroxide was added using a Yamaha 4 hp pump and perforated layflat hose within 3 mins to give a measured concentration of $1800 \mathrm{ppm}$ by the potassium permangamate titration method after Vogel (1978). The tarpaulin was dropped after 16 mins and the cage flushed by boat.

\section{Results and discussion}

When the tarpaulin was placed alongside the cage oxygen saturation remained at ambient $(100 \%)$ at $50 \mathrm{~cm}$ depth but dropped to $75 \%$ saturation at $2 \mathrm{~m}$ and $65 \%$ at $3 \mathrm{~m}$. Saturation increased to $100 \%$ at 2 and $3 \mathrm{~m}$ depth when the oxygen ring was inserted but dropped to $75-80 \%$ when the tarpaulin enclosed the cage. When the hydrogen peroxide was pumped in, oxygen saturation remained stable to the end of treatment at $50 \mathrm{~cm}$ and increased gradually during treatment to $90-95 \%$ of ambient. At the end of the treatment saturation dropped sharply to $85 \%$ of ambient at the surface and to 70 and $60 \%$ respectively at 2 and $3 \mathrm{~m}$. When the cage was flushed with an outboard motor oxygen saturation increased to $170-180 \%$ (Fig. 2).

These results suggest that oxygen saturation was sufficiently' high during treatment. However, critical points identified were: the need to monitor oxygen at lower levels in the cage in addition to the surface; the need to supply adequate oxygen between applying the tarpaulin and delivery of the

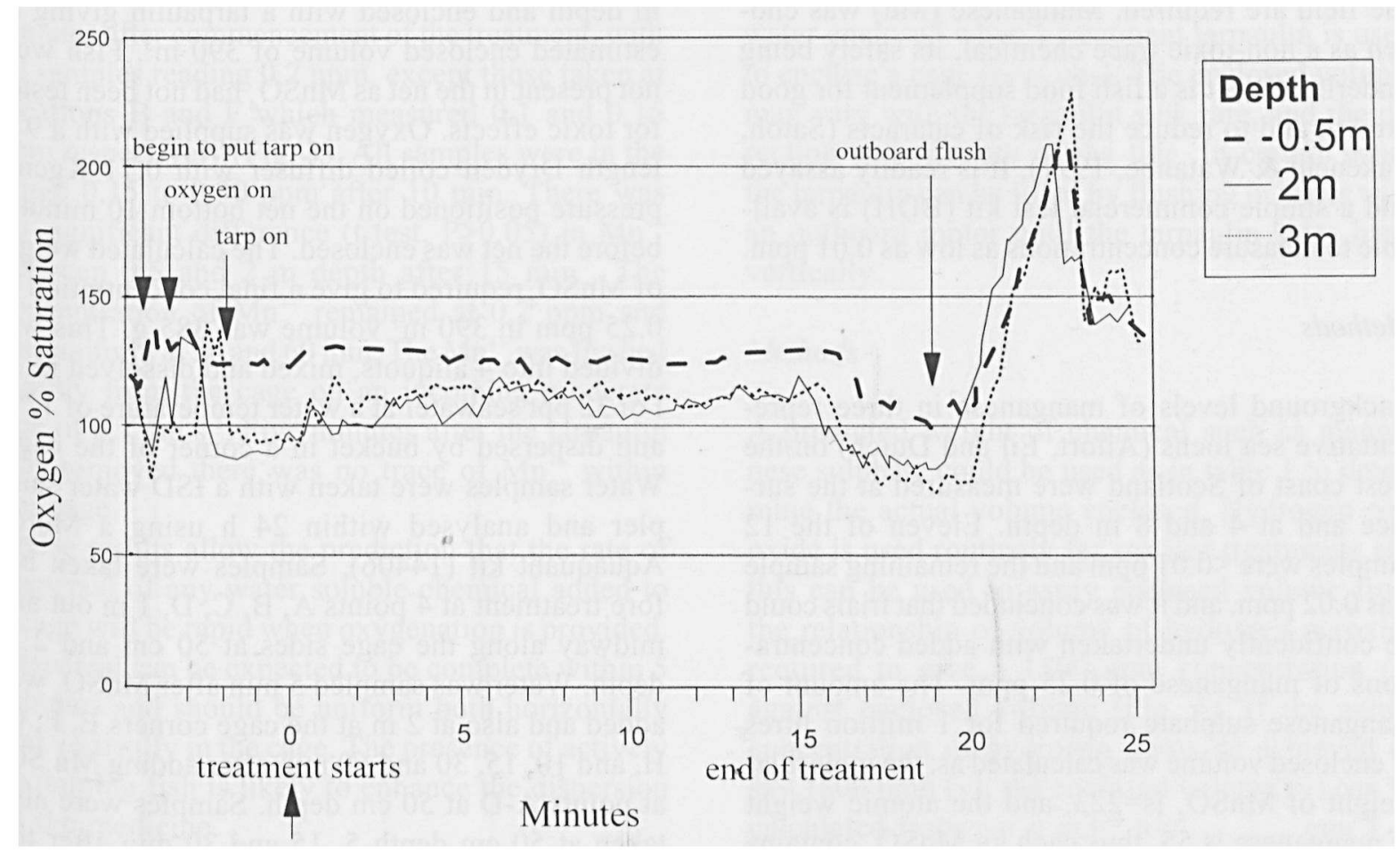

Fig. 2. Oxygen saturation during a sea lice treatment with hydrogen peroxide. 
hydrogen peroxide which itself releases oxygen as it breaks down; and oxygen saturation was low following removal of the tarpaulin. The decline may be due to increased ventilation following removal of the tarpaulin and additional stress. Reduced oxygen saturation could explain reported burrowing of fish into folds in the net and resulting fish damage and sometimes crushing (pers.obs.) when fish drop to the net bottom following a difficult treatment. Continued aeration of the cage with oxygen or compressed air or by flushing by boat is recommended to maintain oxygen saturation and to encourage fish to swim off the net bottom.

\section{Rate and pattern of dispersal of chemotherpeutants within the cage}

The rate of horizontal and vertical dispersal of the medicine in the cage may be a problem and there could be areas of medicine at high concentration. It may be possible to take samples of Aquagard at regular intervals to measure dispersal rate but elaborate analytical techniques that cannot be used in the field are required. Manganese (Mn) was chosen as a non-toxic trace chemical, its safety being underlined as it is a fish food supplement for good growth and to reduce the risk of cataracts (Satoh, Takeuchi \& Watanbe, 1991). It is readily assayed and a simple commercial test kit (BDH) is available to measure concentrations as low as $0.01 \mathrm{ppm}$.

\section{Methods}

Background levels of manganese in three representative sea lochs (Ailort, Eil and Duich) on the west coast of Scotland were measured at the surface and at 4 and $8 \mathrm{~m}$ depth. Eleven of the 12 samples were $<0.01 \mathrm{ppm}$ and the remaining sample was $0.02 \mathrm{ppm}$, and it was concluded that trials could be confidently undertaken with added concentrations of manganese of $0.25 \mathrm{ppm}$. The amount of manganese sulphate required for 1 million litres of enclosed volume was calculated as: the molecular weight of $\mathrm{MnSO}_{4}$ is $=223$, and the atomic weight of manganese is 55 , thus each $\mathrm{kg} \mathrm{MnSO}$ contains $55 / 223 \times 1000 \mathrm{~g} \mathrm{Mn}=247 \mathrm{~g}$, therefore, $1 \mathrm{~kg}$ of
Table 1. Calculation of enclosed volume from measured manganese concentration after adding a fixed mass of manganese ( $250 \mathrm{~g}$, or $1 \mathrm{~kg}$ manganese sulphate).

\begin{tabular}{lc}
\hline $\begin{array}{l}\text { Observed Mn } \\
\text { conc (ppm) }\end{array}$ & $\begin{array}{l}\text { Volume } \\
\text { enclosed (l) }\end{array}$ \\
\hline 1.000 & 250,000 \\
0.500 & 500,000 \\
0.330 & 750,000 \\
0.250 & $1,000,000$ \\
0.200 & $1,250,000$ \\
0.167 & $1,500,000$ \\
0.143 & $1,750,000$ \\
0.125 & $2,000,000$ \\
\hline
\end{tabular}

$\mathrm{MnSO}_{4}$ is required to give a manganese concentration of $0.25 \mathrm{ppm}$ in 1 million litres of enclosed volume. The relationship between observed concentration and enclosed volume is given in Table 1.

Differences in the final measured concentrations at different points in the cage would show inadequate mixing, and mixing rates could be monitored by plotting the rate of progress to the final observed maximum concentration.

A net on a $11.4 \mathrm{~m}$ square cage was raised to 3 $m$ depth and enclosed with a tarpaulin giving an estimated enclosed volume of $390 \mathrm{~m}^{3}$. Fish were not present in the net as $\mathrm{MnSO}_{4}$ had not been tested for toxic effects. Oxygen was supplied with a $9 \mathrm{~m}$ length Dryden coiled diffuser with $0.71 \mathrm{Kgcm}^{-2}$ pressure positioned on the net bottom 10 minutes before the net was enclosed. The calculated weight of $\mathrm{MnSO}_{4}$ required to give a final concentration of $0.25 \mathrm{ppm}$ in $390 \mathrm{~m}^{3}$ volume was $385 \mathrm{~g}$. This was divided into 4 aliquots, mixed and dissolved in 10 1 of 32 ppt seawater at a water temperature of $12^{\circ} \mathrm{C}$ and dispersed by bucket in a corner of the cage. Water samples were taken with a ISD water sampler and analysed within $24 \mathrm{~h}$ using a Merck Aquaquant kit (14406). Samples were taken before treatment at 4 points $A, B, C, D, 1 \mathrm{~m}$ out and midway along the cage sides at $50 \mathrm{~cm}$ and $2 \mathrm{~m}$ depth. Water was sampled 5 min after $\mathrm{MnSO}_{4}$ was added and also at $2 \mathrm{~m}$ at the cage corners E, F, G, $\mathrm{H}$, and $10,15,30$ and 60 min after adding $\mathrm{Mn} \mathrm{SO}_{4}$ at points A-D at $50 \mathrm{~cm}$ depth. Samples were also taken at $50 \mathrm{~cm}$ depth 5,15 and $30 \mathrm{~min}$ after the tarpaulin was dropped. 


\section{Mn ppm}

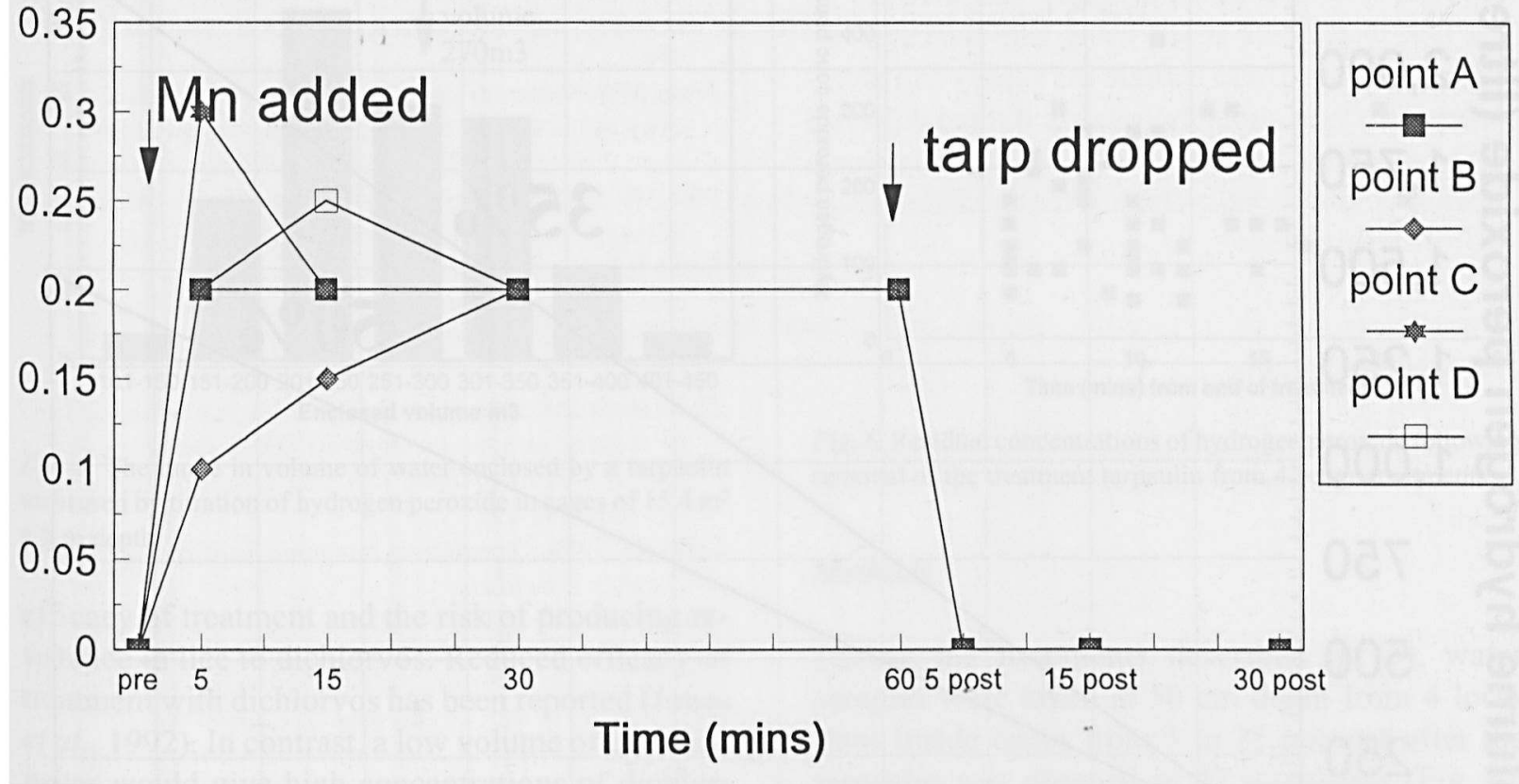

Fig. 3. Dispersion of manganese within a 12 metre cage enclosed with a tarpaulin.

\section{Results and discussion}

An even concentration of $\mathrm{Mn}^{++}$was measured 5 minutes after commencement of the treatment, with all samples reading $0.2 \mathrm{ppm}$, except those taken at locations B and F which measured 0.1 and 0.15 ppm respectively (Fig. 3). All samples were in the range 0.15 to $0.30 \mathrm{ppm}$ after $10 \mathrm{~min}$. There was no significant difference ( $t$ test, $\mathrm{P}>0.05$ ) in $\mathrm{Mn}^{++}$ between 0.5 and $2 \mathrm{~m}$ depth after $15 \mathrm{~min}$. The concentration of $\mathrm{Mn}^{++}$remained at $0.2 \mathrm{ppm}$ and was uniform at 30 and $60 \mathrm{~min}$. The $\mathrm{Mn}^{++}$was flushed rapidly from the cage on an incoming moderate tide of $6.7 \mathrm{~cm} \mathrm{~s}^{-1}$. Five minutes after the tarpaulin was removed there was no trace of $\mathrm{Mn}^{++}$within the cage.

These results allow the prediction that the rate of dispersal of any water soluble chemical added to a cage will be rapid when oxygenation is provided. Dispersal can be expected to be complete within 5 minutes and should be uniform both horizontally and vertically in the cage. The presence of actively swimming fish is likely to enhance the dispersion of the medicine.

\section{Variation in the volume of enclosed water}

An area of risk is the highly variable volume of water enclosed when a treatment tarpaulin is used to enclose a cage (pers.obs). The enclosed volume may vary with the tarpaulin sink rate, and the direction and strength of the tide. In certain cases the tarpaulin can be filled by flushing in water with an outboard motor until the tarpaulin sides hang vertically.

\section{Methods}

A predicted weight of chemical such as manganese sulphate could be used as in table 1 to determine the actual volume enclosed. Hydrogen peroxide is used routinely for sea lice treatments and this can be used to assay enclosed volume from the relationship of volume of hydrogen peroxide required to give a $1500 \mathrm{ppm}$ concentration (x) against enclosed volume (Fig. 4). If the actual concentration of hydrogen peroxide achieved is, say, $1800 \mathrm{ppm}(\mathrm{y})$, the enclosed volume (v) can be calculated from: $v=v \mathrm{~m} 3 * \mathrm{x} / \mathrm{y}$ eqn 1.

To examine the range in enclosed volumes in routine treatments with hydrogen peroxide record- 


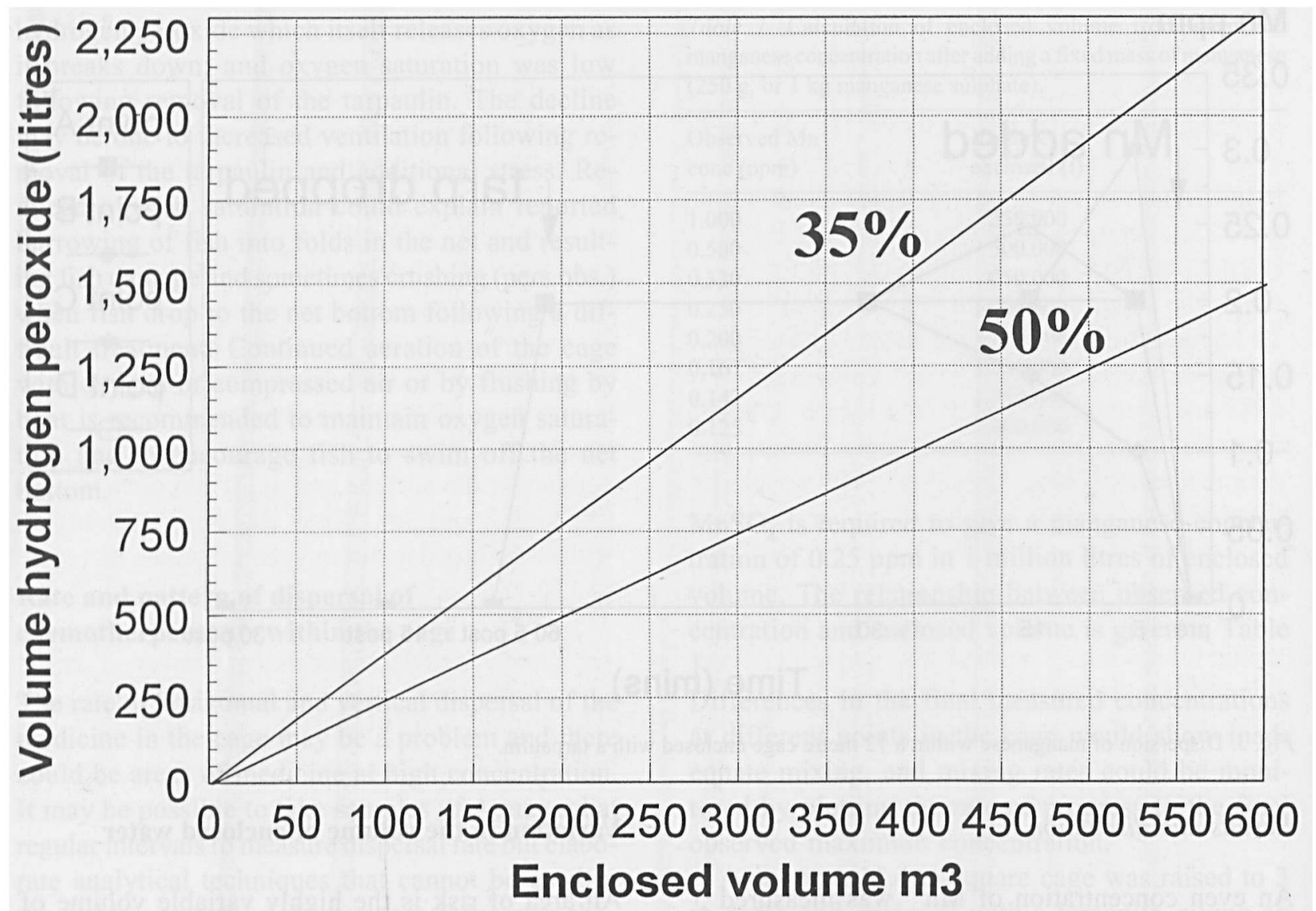

Fig.4. Nomograph for calculation of enclosed water volume from quantity of hydrogen peroxide added to an enclosed cage to achieve a concentration of $1500 \mathrm{ppm}$. Data supplied by Solvay Interox, Warrington, Cheshire.

ings were made from 86 treatments of fish (900012000 per cage of $3 \mathrm{~kg}$ mean weight, stocking densities $14.2-19.0 \mathrm{~kg} \mathrm{~m}^{-3}$ per cage) in 15.4 square Wavemaster steel cages. The net was split at a stanchion $8.8 \mathrm{~m}$ in to reduce the amount of hydrogen peroxide required, and the fish were confined in the reduced area. The treated volume was calculated as $15.4 \mathrm{~m} \times 8.8 \mathrm{~m} \times 2 \mathrm{~m}$ depth $=271 \mathrm{~m}^{3}$. This value was compared with the actual volumes calculated from eqn 1 . Water temperature was $13^{\circ} \mathrm{C}$, salinity $29 \mathrm{ppm}$ and current velocity varied from 0 to $9 \mathrm{~cm}^{-1} \mathrm{~s}^{-1}$ during the treatments. The hydrogen peroxide was dispensed with a pump with pre-mixing, approximately 50:50 with seawater. The volume of hydrogen peroxide was measured using a Weston flowmeter. Oxygen was supplied through two $3 \mathrm{~m}$ Dryden diffusers $2 \mathrm{~m}$ from the edge of the cage 5 mins prior to enclosure and throughout the treatment. Water samples were taken from 4 points in the treatment cage at ca. $50 \mathrm{~cm}$ depth 7 mins after the hydrogen peroxide was discharged and the concentration assayed using the potassium permanganate titration method after Vogel (1978). If the target concentration of $<1500 \mathrm{ppm}$ was not achieved a further volume of chemical was added and another assay performed.

\section{Results and discussion}

The range in enclosed volumes was high, from 124 to $450 \mathrm{~m}^{3}$ in 86 treatments (Fig. 5), representing $46-166 \%$ of the theoretical enclosed volume. The greatest volume was 3.6 times the lowest. If this were the case during a treatment with Aquagard, the dichlorvos concentrations would range from $0.46-1.66$ of the target of $1 \mathrm{ppm}$; thus 40 of the 86 treatments. would be less than the target concentration. This would increase the possibility of poor 


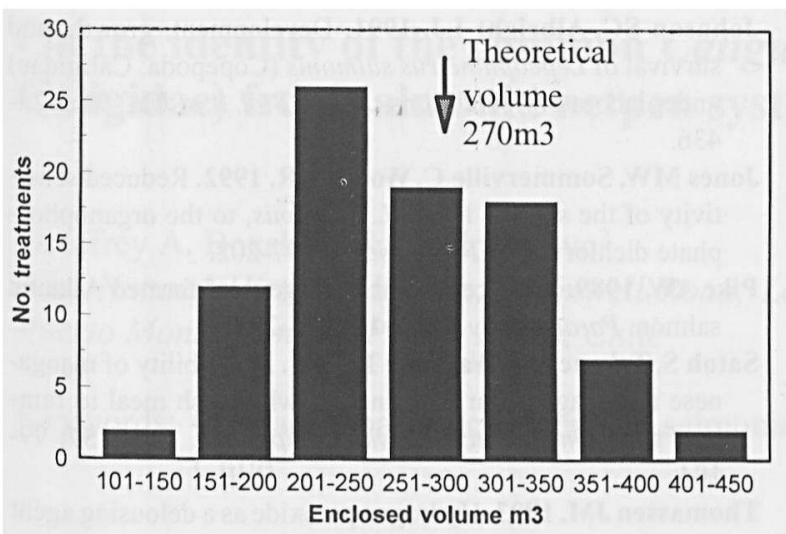

Fig. 5. The range in volume of water enclosed by a tarpaulin measured by titration of hydrogen peroxide in cages of $15.4 \mathrm{~m}^{2}$ $x 8 \mathrm{~m}$ depth.

efficacy of treatment and the risk of producing resistance in lice to dichlorvos. Reduced efficacy of treatment with dichlorvos has been reported (Jones et al., 1992). In contrast, a low volume of enclosed water would give high concentrations of dichlorvos in certain treatments, a risk to fish health and adverse reactions have been reported (pers. obs.). These reported treatments were carried out using a flat tarpaulin and it is recommended that a wedge shaped tarpaulin should be used to reduce the variation in enclosed volume and a consistent method used for raising the net and applying the tarpaulin. More consistent volumes in hydrogen peroxide treatments ensures that, in most cases, a fixed volume of medicine can be used, giving the optimum concentration for the duration of most of the treatment, thus increasing its efficacy.

\section{Residual medicine in the cage following treatment}

In several reported adverse reactions following treatments with hydrogen peroxide (pers. obs.), salmon became lethargic with some mortalities up to 30-60 minutes after the tarpaulin was dropped although they had been healthy on termination of the treatment. This suggests that it may take a prolonged time for hydrogen peroxide to disperse from the cages and residence time may be variable, depending on tidal state.The dispersal rate of hydrogen peroxide from cages was, therefore, examined.

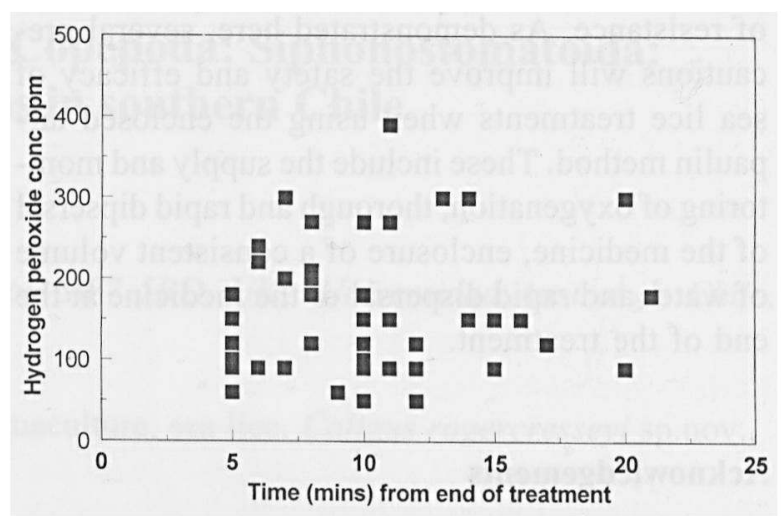

Fig. 6. Residual concentrations of hydrogen peroxide following removal of the treatment tarpaulin from 42 cage treatments.

\section{Methods}

During the treatments described in (3), water samples were taken at $50 \mathrm{~cm}$ depth from 4 locations inside cages from 5 to 25 minutes after the tarpaulin was dropped in 42 treatments (Fig. 6). Hydrogen peroxide concentration was analysed by the potassium permanganate titration method after Vogel (1978).

\section{Results and discussion}

The concentration of residual hydrogen peroxide varied considerably between treatments, from 50 to 400 ppm 5-15 minutes from the tarpaulin being dropped. Low concentrations of hydrogen peroxide can still be toxic to salmon (Thomassen, 1993) and, although concentrations of $<200 \mathrm{ppm}$ are unlikely to give problems, residues should be measured following treatment and arrangements made to disperse the medicine if concentrations exceed $200 \mathrm{ppm}$ for more than $10 \mathrm{~min}$ from the end of treatment. The cage could be flushed to disperse hydrogen peroxide and to revive lethargic fish by encouraging them to swim off the bottom of the net.

\section{Conclusions}

Adverse reactions using currently licensed medicines such as Aquagard and hydrogen peroxide have been reported, involving inappetance, reduced efficacy of treatment, mortality and the development 
of resistance. As demonstrated here, several precautions will improve the safety and efficacy of sea lice treatments when using the enclosed tarpaulin method. These include the supply and monitoring of oxygenation, thorough and rapid dipsersal of the medicine, enclosure of a consistent volume of water and rapid dispersal of the medicine at the end of the treatment.

\section{Acknowledgements}

We thank Maureen Berry and Graeme MacKenzie for assistance and Dunstaffnage Marine Laboratory for the loan of oxygen loggers.

\section{References}

Costello MJ. 1993. Review of methods to control sea lice (Caligidae: Crustacea) infestations on salmon (Salmo salar) farms. In: Boxshall GA \& Defaye D, Pathogens of wild and farmed fish: Sea Lice. Chichester. Ellis Horwood, 219-252.
Johnson SC, Albright LJ. 1991. Development, growth, and survival of Lepeophtheirus salmonis (Copepodax Caligidae) under laboratory conditions. J. Mar Biol. Ass. U.K. 71 : 425 436.

Jones MW, Sommerville C, Wootten R. 1992. Reduced sensitivity of the salmon louse, $L_{*}$ salmonis, to the organophosphate dichlorvos. J. Fish Dis. 15: 197-202.

Pike AW, 1989. Sea lice: major pathogens of farmed Atlantic salmon, Parasitology Today 15: 291-297.

Satoh S, Takeuchì T, Watanbe T. 1991. Availability of manganese and magnesium contained in white fish meal to rainbow trout Oncorhynchus mykiss. Nippon. s. Gakk. 57: 99104.

Thomassen JM. 1993. Hydrogen peroxide as a delousing agent for Atlantic salmon. In: Boxshall GA \& Defaye D, Pathogens of wild and farmed fish: Sea Lice. Chichester: Ellis Horwood, 290-295.

Vogel AI. 1978. Quantitative Inorganic Analysis, 4th edition. England: Longman.

Wootten R, Smith JW, Needham, EA. 1982. Aspects of the biology of the parasitic copepods Lepeophtheirus salmonis and Caligus elongatus on farmed salmonids, and their treatment. Proc. R. Soc. Edinb, 81B: 185-197.

Received: 4 January 1999 